\title{
ТЕОРЕТИЧЕСКИЕ ОСНОВЫ ФОРМИРОВАНИЯ ПРОФЕССИОНАЛЬНО-ЭТИЧЕСКИХ КАЧЕСТВ КУРСАНТОВ ВЕДОМСТВЕННЫХ ВУЗОВ СИЛОВЫХ СТРУКТУР РОССИЙСКОЙ ФЕДЕРАЦИИ В СОВРЕМЕННЫХ УСЛОВИЯХ
}

\section{THEORETICAL BASES OF FORMATION OF PROFESSIONAL-ETHICAL QUALITIES OF CADETS OF DEPARTMENTAL UNIVERSITIES OF POWER STRUCTURES OF THE RUSSIAN FEDERATION UNDER MODERN CONDITIONS}

\section{Komov}

Summary: The article presents a theoretical analysis of the formation of professional and ethical qualities of cadets of departmental universities of the power structures of the Russian Federation in modern conditions. The role of professional ethics of military personnel from the point of view of internal control and management of service behavior in future professional activities and regulation of relationships in the social space is considered.

Keywords: professional ethics, professional culture, formation of professional and ethical qualities of cadets, professional and moral education, code of ethics, educational environment.

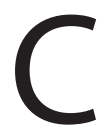
реди угроз национальным интересам России всё чаще выделяют угрозу нравственному здоровью нации, «размывание традиционных российских духовно-нравственных ценностей и ослабление единства многонационального народа Российской Федерации путём внешней культурной и информационной экспансии (включая распространение низкокачественной продукции массовой культуры), пропаганда вседозволенности и насилия, расовой, национальной и религиозной нетерпимости»[2]. В связи с этим, большая ответственность за поддержание социальной стабильности и упрочение нравственных основ российского государства, за обеспечение прав и свобод его граждан, за внутреннюю и внешнюю безопасность страны возлагается на органы исполнительной власти в лице силовых структур.

Социальный характер деятельности различных министерств и ведомств в сфере обеспечения безопасности государства, общества и личности во многом определяется состоянием профессиональной культуры сотрудников, их качественным составом, профессиональной и психологической подготовкой и готовностью к выполнению возложенных на них обществом функций.
Комов Марат владимирович г. Хабаровск
наститет, maratkom@mail.ru

Аннотация: В статье представлен теоретический анализ формирования профессионально-этических качеств курсантов ведомственных вузов силовых структур Российской Федерации в современных условиях. Рассмотрена роль профессиональной этики военнослужащих с точки зрения внутреннего контроля и управления служебным поведением в будущей профессиональной деятельности и регулирования взаимоотношений в социальном пространстве.

Ключевые слова: профессиональная этика, профессиональная культура, формирование профессионально-этических качеств курсантов, профессионально-нравственное воспитание, кодекс этики, воспитательная среда.

Поэтому актуальной задачей науки и практики становится выявление основ формирования кадрового корпуса военнослужащих силовых ведомств в соответствии с их деловыми профессиональными, и этическими качествами. В силу своей организованности, традиционной сплочённости, профессионализма и компетентности военная служба может стать фактором стабилизации и нравственного оздоровления общества.

В вопросе профессионального и этического совершенствования и развития необходимых качеств сотрудника силовых ведомств, а также профессиональном становлении военнослужащего отводится периоду обучения в ведомственной образовательной организации, во время которого, формируются профессиональноэтические качества и закладываются основы его эффективной деятельности в будущем. Следует понимать, что образ курсанта военного вуза всегда ассоциировался с высоким уровнем профессионального образования и нравственного воспитания в лучших традициях офицерского братства, обеспечивающих способность и готовность противостоять внешним и внутренним угрозам обществу и государству. Однако современные угрозы 
требуют поиска новых методов профилактики и борьбы с ними.

Значительный вклад в разработку теории и практики воспитания курсантов внесли такие педагоги и психологи как: А.В. Барабанщиков, В.П. Давыдов, Э.П. Утлик, Н.Ф. Феденко [7], В.И. Вдовюк [9], Д.А. Волкогонов [10], И.В. Горлинский [11] и многие другие. Вопросы формирования профессионально-этических качеств военнослужащих и курсантов в своих научных работах рассматривали В.А. Сухарев [18], А.В. Мяготин [15], М.В. Ермолов [13].

Несмотря на наличие обширного научного и эмпирического материала в этой области, проблема формирования профессионально-этических качеств курсантов ведомственных вузов силовых структур в новых социально- экономических и культурных условиях развития общества остаётся недостаточно исследованной.

Основы государственной культурной политики Российской Федерации гласят, что основной миссией культуры является передача новым поколениям свода нравственных, моральных, этических ценностей, составляющих основу национальной самобытности. Культура представляет собой всеобъемлющее, широкое и важное явление в жизни государства, народа, нации [1]. Одним из её аспектов является воспитательное воздействие. Рассматривая воспитание как отдельный феномен, можно выявить, что эти два явления - культура и воспитание - взаимосвязаны и взаимодополняют друг друга, так воспитание способствует сохранению культуры, а культура способствует эффективности воспитания.

В рамках изучения теоретических основ формирования профессионально-этических качеств курсантов ведомственных вузов силовых структур категория воспитания как процесса является необходимой, поскольку данный процесс отличается продолжительностью - человек учится и воспитывается на протяжении всей своей жизни. Тогда, условно, процесс воспитания можно разделить на следующие периоды: воспитание в семье или период детства, детский сад, школа, институт и профессиональная деятельность.

Учитывая такую периодизацию, нельзя не отметить важность воспитания как одну из составляющих подготовки курсантов. Воспитание в ведомственных вузах является одним из основных компонентов образовательной деятельности и призвано способствовать формированию профессионально-этических качеств, ценностных установок, мировоззренческих позиций и убеждений будущего сотрудника, соответствующих профессиональному предназначению и культурному запросу общества.

Для уточнения цели и задач воспитательной работы ведомственных вузов силовых структур в аспекте формирования профессионально-этических качеств курсантов выделим определение термина «формирование».

Формирование - сознательное управление процессом развития человека или отдельных сторон личности, качеств и свойств характера и доведение их до задуманной формы (уровня, образа, идеи). В педагогической практике формирование означает применение приёмов и способов (методов, средств) воздействия на личность обучающегося с целью создания у него системы определённых ценностей и отношений, знаний и умений, склада мышления и памяти [8].

Иными словами можно сказать, что задачей воспитательной работы ведомственных вузов является целенаправленное применение методов и средств воздействия на курсантов или отдельные стороны его личности, качества и свойства характера с целью создания у него профессионально-этических качеств, ценностных установок, мировоззренческих позиций и убеждений будущего сотрудника, представляющего ведомство, соответствующих профессиональному предназначению.

Чтобы понять, как эффективно формировать профессионально-этические качества курсантов ведомственных вузов силовых структур, необходимо рассмотреть определение понятия «профессиональная этика».

В современной отечественной науке наблюдается рост интереса к данной проблематике и многие учёные в своих работах исследуют данное понятие. Энциклопедические словари определяют общетеоретическую этику как научную дисциплину, объектом изучения которой является мораль, нравственность [12]. Этика как философская наука возникла в середине I тысячелетия до н.э. вследствие необходимости систематизации моральных норм, явившихся результатом отделения духовно-теоретической деятельности от материально-практической. Одним из видов материально-практической деятельности человека являлась профессиональная деятельность. Поэтому ещё в эпоху античности, как составная часть общей этической теории, возникает профессиональная этика.

Профессиональная этика определяется словарями как совокупность норм, которые регулируют личное и профессиональное поведение [5]. Исследователи в области этики А.А. Гусейнов, И.С. Кон определяют профессиональную этику в двух ипостасях: во-первых, - это кодексы поведения, предписывающие определённый тип нравственных взаимоотношений между людьми, которые представляются оптимальными с точки зрения выполнения ими своей профессиональной деятельности, во-вторых, - способы обоснования данных кодексов, социально-философское истолкование культурно-гумани- 
стического назначения данной профессии, её этоса [6].

Кодекс профессиональной этики военнослужащих внутренних войск МВД России «представляет собой свод общих принципов профессиональной служебной этики и основных правил служебного поведения, которыми надлежит руководствоваться военнослужащим внутренних войск МВД России независимо от замещаемой воинской должности...» и «...служит основой для формирования должной морали в сфере военной службы во внутренних войсках, уважительного отношения к внутренним войскам в общественном сознании, а также выступает как институт общественного сознания и нравственности военнослужащих внутренних войск, их самоконтроля...» [3].

П.П. Степнов определяет понятие профессиональной этики как «отражение нравственного сознания, взаимоотношений и поведения людей, которые обусловлены спецификой профессиональной деятельности» [17]. То есть, профессиональная этика в среде курсантов ведомственных вузов силовых структур - это сознательно усвоенная и внутренне принятая система принципов, ценностей и норм поведения регулирующая отношения внутри коллектива.

А.А. Солоницына формулирует профессиональную этику как «совокупность определённых обязанностей и норм поведения, поддерживающих моральный престиж профессиональных групп в обществе» [16]. В этом контексте представляются весьма актуальными такие направления воспитательной работы военных вузов России как профессиональное и нравственное воспитание курсантов, содействующее формированию понятий о нравственных нормах, принятых в российском обществе и общевоинских уставах, значении вооружённых сил для обеспечения безопасности общества, правилах служебного поведения, содействующих укреплению доверия граждан к силовым структурам.

Н.Н. Шувалова представляет профессиональную этику как науку, «объектом которой является профессиональная мораль как один из срезов общественной нравственности, то есть особенности нравственного сознания и поведения людей определённого вида профессии, которые объясняются их профессиональной принадлежностью; как нормативную дисциплину, включающую анализ типичных этических ситуаций, связанных с профессиональной деятельностью, и их рациональное обоснование: свод норм и правил профессиональной морали, то есть этический кодекс» [19].

Несомненно, профессионально-этические качества курсантов вузов силовых ведомств должны формироваться в соответствии с нравственными нормами и требованиями российского общества и отражать его инте- ресы, несмотря на профессиональные особенности не должны идти в разрез с ними. Так, «Типовой кодекс этики и служебного поведения государственных служащих Российской Федерации и муниципальных служащих» разработан в соответствии с положениями Конституции Российской Федерации, федеральных законов от 25 декабря 2008 г. № 273-Ф3 «О противодействии коррупции», от 27 мая 2003 г. № 58-Ф3 «О системе государственной службы Российской Федерации», от 2 марта 2007 г. Указа Президента Российской Федерации от 12 августа 2002 г. № 885 «Об утверждении общих принципов служебного поведения государственных служащих» и иных нормативных правовых актов Российской Федерации, а также основан на общепризнанных нравственных принципах и нормах российского общества и государства [4].

Ермолов М.В. раскрывает понятие «профессиональная этика офицера» как «сложившаяся в рамках профессии офицера совокупность ценностей, норм и принципов, которыми он руководствуется в своей служебной и повседневной деятельности и как высший уровень свойств саморегуляции офицера, когда основными ориентирами в его профессиональной деятельности и повседневной жизни становятся непреходящие профессионально-нравственные ценности» [14].

Данная формулировка даёт основание утверждать, что формирование профессионально-этических качеств курсантов ведомственных вузов силовых структур Российской Федерации играет важную роль не только с точки зрения внутреннего контроля и управления служебным поведением в будущей профессиональной деятельности, но и внешнего регулирования взаимоотношений в социальном пространстве.

Следовательно, уточняя некоторые аспекты рассматриваемого феномена, можно дать определение, что профессиональная этика - это совокупность сознательно принятых принципов, обусловленных особенностями и традициями профессиональной деятельности, регулирующих взаимоотношения внутри профессиональных групп и сообществ, ценностей, отражающих интересы и культуру общества, норм поведения в социальном пространстве укрепляющих моральный престиж и самобытность профессии, а также личностных качеств, влияющих на эффективность профессиональной деятельности.

Для собственного определения содержания понятия «профессионально-этические качества курсанта» обратимся к сформулированному выше определению «профессиональная этика» и рассмотрим понятие «качества личности».

Качества личности - особенности проявления личности, выражающие специфику психологических процессов и состояний, черт характера и поведения в социаль- 
ной или природной среде. Качества личности - всегда субъектны. Они имеют количественные характеристики и могут измеряться по уровню, степени или стадии развития. Качества личности одновременно и устойчивы на момент измерения, и динамичны, то есть находятся в постоянном развитии за период жизни человека. Их формирование и изменение зависит от многих условий: биологических и социальных [8].

Так, курсанты имеют различный уровень и содержание жизненного опыта, качества образования, отношения к окружающим, психо-физиологического развития. Их представления об этической стороне профессиональной деятельности часто характеризуются неполнотой и являются фрагментарными. В процессе обучения предыдущие представления изменяются, корректируются, обобщаются и у курсантов вырабатывается определённая модель их профессиональной деятельности, формируются черты характера, поведения, в том числе, их профессионально-этические качества.

Важными качествами личности курсантов военных вузов, определяющими их профессиональную культуру и позволяющими эффективно выполнять учебные, а в дальнейшем служебные задачи являются дисциплинированность, исполнительность, ответственность, бдительность, самостоятельность, инициативность, настойчивость, целеустремлённость, а также такие аспекты общей культуры личности, как грамотность, эрудированность, компетентность, духовность, этика и т. д

Систематизируя вышесказанное, можно интерпретировать профессионально-этические качества курсанта как особенности проявления личности курсанта, выражающие специфику сознательно принятых принципов, обусловленных особенностями и традициями профессиональной деятельности, регулирующих взаимоотношения внутри профессиональных групп и сообществ; ценностей отражающих исторически сложившиеся интересы и культуру общества; норм поведения в социальном пространстве укрепляющих авторитет и доверие к военнослужащим среди граждан; качеств общей культуры личности, которые находят своё проявление во время образовательного процесса и обеспечивают предпосылки для дальнейшего развития.

К биологическим условиям, от которых зависит формирование профессиональных качеств курсантов ведомственных вузов силовых структур, можно отнести результаты, проводимого при приёме среди абитуриентов, профессионально-психологического отбора, целью которого является не только установление возможности испытуемого усваивать общеобразовательную программу, но и определение его личностных характеристик на предмет соответствия той или иной специальности пригодным к профессии считается человек, который по своим индивидуальным данным соответствует требованиям, предъявляемым ему профессией.

К социальным условиям формирования профессионально важных качеств курсантов относится образовательная и воспитательная среда военного вуза, где образовательная среда - это совокупность как объективно существующих, так и специально созданных общественных, педагогических и материальных условий ведомственного образования, оказывающих целенаправленное воздействие на формирование и развитие личности курсанта.

Воспитательная среда военного вуза включает:

- идеологию, господствующую в современном российском обществе;

- нравственно-духовные установки, принятые в офицерском корпусе;

- единые требования к моральному облику военнослужащего;

- взаимоотношения, складывающиеся в воинских коллективах и порядок разрешения возникающих в них конфликтов;

- отношения офицеров к событиям, происходящим в стране и за рубежом, степень их совпадения с официальной государственной политикой;

- соблюдение законов со стороны преподавательского состава, командиров и начальников, уважение ими личного достоинства курсантов;

- положительные факты проявления корпоративности в офицерской среде.

Воспитательная среда военного вуза должна обеспечить восприятие курсантами общественно-исторического опыта, планомерное и целенаправленное воздействие на их сознание и поведение, в целях формирования у курсантов государственно-патриотического сознания, верности России, гордости за принадлежность к вооружённым силам и их офицерскому корпусу, понятия офицерской чести и достоинства, высокой нравственной культуры и профессиональной этики. Полученное в военном вузе образование должно перерастать в высокую профессиональную культуру.

Современные условия характеризуются изменениями в экономической, социальной и культурной сферах жизнедеятельности общества, обусловленными внешними и внутренними угрозами национальным интересам России. Обеспечение государственной безопасности, стабильности в обществе, поддержание нравственных основ государства во многом зависит от профессиональной культуры и морально-нравственного состояния кадрового корпуса Вооружённых Сил России, в связи с чем на одно из ведущих мест выступает необходимость формирования у курсантов военных вузов России профессионально-этических качеств. 
Проведённый теоретический анализ показал значение и важность формирования профессионально-этических качеств курсантов ведомственных вузов силовых структур организаций России в современных условиях, актуализирующих вопросы поиска оптимальных методов формирования профессионально-значимых качеств курсантов и требующих научного обоснования данной проблемы.

\section{ЛИТЕРАТУРА}

1. Указ Президента РФ от 24 декабря 2014 г. N 808 «0б утверждении Основ государственной культурной политики». Консультант Плюс [Электронный pecypc].URL: http://www.consultant.ru/ document/ cons_doc_LAW_172706/ (дата обращения: 30.04.2020).

2. Указ Президента РФ от 31 декабря 2015 г. № 683 «0 Стратегии национальной безопасности Российской Федерации», Консультант Плюс [Электронный pecypc].URL: http://www.consultant.ru/document/cons_doc_LAW_191669/ (дата обращения: 30.04.2020).

3. Приказ МВД РФ от 23 августа 2011 года N 969 «06 утверждении Кодекса профессиональной этики военнослужащих внутренних войск МВД России», Консультант Плюс [Электронный ресурc]. URL: http://www.consultant.ru/document/cons_doc_LAW_120397/ (дата обращения: 30.04.2020).

4. «Типовой кодекс этики и служебного поведения государственных служащих Российской Федерации и муниципальных служащих» (одобрен решением президиума Совета при Президенте РФ по противодействию коррупции от 23 декабря 2010 г. (протокол N 21)). Гарант [Электронный ресурс]. URL: https:// base.garant.ru/55171108 /(дата обращения: 30.04.2020).

5. Словарь по этике. /Под ред. И.С. Кона. - М.: Политиздат, 1981 - С. 431.

6. Словарь по этике /Под ред. А.А. Гусейнова и И.С. Кона. М.: Политиздат, 1989. - С. 278.

7. Барабанщиков А.В., Давыдов В.П., Утлик Э.П., Феденко Н.Ф.; Военная педагогика и психология / Под ред. А.В. Барабанщикова - М.: Воениздат, 1986 - 239 c.

8. Безрукова В.С. Основы духовной культуры (энциклопедический словарь педагога).— Екатеринбург. 2000 - С. $370,823$.

9. Вдовюк, В.И. Основы воспитательной работы с личным составом Вооруженных Сил Российской Федерации: курс лекций. / В.И. Вдовюк, С.М. Фильков; Моск.гос.ин-т междунар. отношений (ун-т) МИД России - М.: МГИМО(У) МИД России, 2003 - 137 с.

10. Волкогонов Д.А. Воинская этика. - М. : Знание, $1980-64$ с.

11. Горлинский И.В. Педагогическая система непрерывного профессионального образования в учебных заведениях МВД России и пути ее развития / И.В. Горлинский. - Москва: Академия МВД России, 1999 - С. 290.

12. Гусейнов А.А. Этика // Новая философская энциклопедия / Ин-т философии РАН; — 2-е изд., испр. и допол.— М.: Мысль, 2010 - 734 с.

13. Ермолов М.В. Сущность и содержание профессионально-этического воспитания курсантов / В.Н. Герасимов, М.В. Ермолов, О.Г. Заец // Мир образования - образование в мире. - 2019. - № 4 (76). - С. 75-80.

14. Ермолов М.В. Совершенствование профессионально-этического воспитания курсантов военных вузов. Дисс. . . кан. пед наук./ФГКВоУ высшего образования «Военный университет» Министерства обороны Российской Федерации-2020 - С. 14.

15. Мяготин А.В. Профессиональная этика государственных служащих. - М., $2005-167$ с.

16. Солоницына А.А. Профессиональная этика и этикет. Учебник. Владивосток: Издательство Дальневосточного университета, 2005 - С. 9.

17. Степнов П.П. Этические нормы государственных служащих. Социально-философский аспект. М., 2000 - С. 51.

18. Сухарев В.А. Социально-профессиональные качества офицера пограничника и их формирование. - М: Академия ФПС России, 2003 - 218 с.

19. Шувалова Н.Н. Административная этика. Учебно-методическое пособие. М.: РАГС, 2010 - С. 19.

(c) Комов Марат Владимирович (maratkom@mail.ru). 